\title{
FEIRA DOS ANEXINS, DE D. FRANCISCO MANUEL DE MELO, E OS PRIMEIROS REGISTROS DE VOCÊ: REVISITANDO IDEIAS DE LONGA DATA NO ESTUDO DAS FORMAS DE TRATAMENTO
}

\author{
FEIRA DOS ANEXINS, BY D. FRANCISCO MANUEL DE MELO, \\ AND THE FIRST RECORDS OF VOCÊ: REVISITING LONG-STANDING \\ IDEAS IN THE STUDY OF ADDRESS FORMS
}

\begin{abstract}
Leonardo Lennertz Marcotulio | Lattes | marcotulio@letras.ufrj.br Universidade Federal do Rio de Janeiro
\end{abstract}

\author{
Daví Lopes Franco | Lattes | davifrancoteacher@gmail.com \\ Universidade Federal do Rio de Janeiro
}

Resumo: Estudos sobre formas de tratamento na história do português costumam mencionar a data de 1666 como primeiro registro de ocorrência da forma Você. Essa informação, tradicionalmente aceita pela literatura e usualmente realizada a partir de Cintra (1972) e Faraco (1996), faz referência à obra Feira dos Anexins, de D. Francisco Manuel de Melo. Embora seja muito divulgado, esse texto ainda permanece desconhecido por parte dos especialistas. Neste sentido, o objetivo deste artigo é dar a conhecer o texto de Melo, assim como problematizar a datação da nova forma de tratamento Você.

Palavras-chave: Formas de tratamento; Você; Feira dos Anexins; D. Francisco Manuel de Melo; Datação.

\begin{abstract}
Studies on address forms in the history of Portuguese have usually referred to 1666 as the first record of the form Você (You). This information, traditionally accepted in the literature and frequently used from Cintra (1972) and Faraco (1996), refers to D. Francisco Manuel de Melo work Feira dos Anexins.. Although, it is widely spread, this text is still unknown by many experts. In this sense, the objectives of this article are to make it well-known and to discuss the dating of the new address forms of Você.
\end{abstract}

Keywords: Forms of address; Você; Feira dos Anexins; D. Francisco Manuel de Melo; Dating. 


\section{Introdução}

Os estudos que se dedicam ao processo de gramaticalização Vossa Mercê > Você consideram que a história da nova forma pronominal Você poderia ser contada a partir do século XVII, momento em que é documentada em textos escritos. O primeiro registro de Você, de acordo com Cintra (1972) e Faraco (1696) - a partir de informações disponibilizadas no dicionário etimológico de Machado (1967) - dataria de 1666 ou pouco antes dessa data, sendo encontrado no texto dramático Feira dos Anexins, de D. Francisco Manuel de Melo.

Embora essa datação tenha sido contestada por Menon (2009), com base em argumentos filológicos e linguísticos, o ano de 1666 parece ter adquirido um valor simbólico na literatura específica sobre o tema. Se, por um lado, abundam os casos de reprodução dessa informação, por outro, o texto de Melo é praticamente desconhecido por parte dos especialistas.

Neste artigo, revisitaremos algumas ideias de longa data na literatura sobre a história das formas de tratamento no português, mais especificamente em relação à datação do primeiro registro da forma Você, dando a conhecer o texto que parece carregar o posto de conter o seu primeiro registro: Feira dos Anexins, de D. Francisco Manuel de Melo.

Para tanto, este texto está organizado da seguinte forma. Na primeira seção, trazemos a literatura mais tradicional sobre as formas de tratamento que estão na base da discussão da primeira abonação de Você, como Cintra (1972), Faraco (1996) e Machado (1967). Na segunda seção, apresentamos com mais detalhes o autor e sua obra: Feira dos Anexins, de D. Francisco Manuel de Melo. A seguir, são apresentados, na seção 3, os argumentos de Menon (2009) sobre a problemática da datação de Você. A análise do texto e dos dados das formas de tratamento em Feira dos Anexins é preocupação da quarta seção. Por fim, na quinta e última seção, esboçamos uma reflexão inicial sobre as diferentes histórias que podem ser contadas sobre a trajetória da forma de tratamento Você se considerarmos as diferenças entre as tipologias textuais utilizadas como fontes de estudo. A essa seção, seguem as considerações finais e as referências bibliográficas.

\section{Sobre a primeira abonação da forma de tratamento você}

A literatura linguística sobre formas de tratamento na história do português coincide em apontar que a forma Você já seria registrada no século XVII, tendo sido documentada pela primeira vez em Feira dos Anexins, de D. Francisco Manuel de Melo, obra de 1666.

Onde estaria disponível essa informação? Percorrendo a literatura clássica sobre a forma de tratamento Você, nos encontramos com a obra fundacional de Luís F. Lindley Cintra (1972), Sobre formas de tratamento na língua portuguesa, na qual podemos ler na página 27: 
Preocupação de muitos, antes de mais nada, em não serem tratados por Vossa Mercê e muito menos por uma das formas fonéticas decadentes vossancê ou você (esta última, salvo erro, atestada até agora pela primeira vez pouco antes de 1666 $)^{14}$, formas abreviadas intimamente associadas à degradação semântica da já antiga fórmula de cortesia (CINTRA, 1972, p. 27, grifo nosso).

A partir da leitura de Cintra, é possível obter a informação de que o primeiro registro de Você teria sido registrado pouco antes de 1666. De modo a complementar essa informação, o leitor é remetido à nota de número 14, que diz:

Exemplo recolhido na Feira de Anexins ${ }^{1}$, de D. Francisco Manuel de Melo (p. 196 da ed. de 1916), por José Pedro Machado, Dicionário Etimológico da Língua Portuguesa, II, p. 2180 b. (CINTRA, 1972, p. 37)

É interessante observar que, ao menos a partir da obra de Cintra (1972), não há a informação de uma datação exata, mas sim de uma obra específica. $O$ primeiro registro de Você, para o autor, estaria presente em Feira dos Anexins, obra de D. Francisco Manuel de Melo, consultada a partir da edição de 1916. Como se verá mais adiante, a obra em questão é póstuma e não se sabe, até o momento, quando exatamente teria sido elaborada. $\mathrm{O}$ ano de 1666 surge, assim, como termo cronológico máximo para a redação da obra, por ter sido esse o ano de morte do autor.

Para a elaboração de seu comentário, Cintra (1972) teria utilizado como fonte de consulta o Dicionário Etimológico da Língua Portuguesa, de José Pedro Machado. Vejamos o que nos diz o dicionarista:

Vossemecê, pron. Está por vossa mercê; daí vosmecê; deste, devido à rapidez da pronúncia da palavra, você; no séc. XVII: “... nem me pisque os olhos, que vossê da história não sabe pisca”, D. Francisco Manuel de Melo, Feira de Anexins, p. 196, ed. de 1916. (MACHADO, 1967, p. 2.319)

Vemos, na obra de Machado (1967), que a referência se restringe à obra Feira dos Anexins, em edição de 1916. Vale ressaltar que o exemplo ao qual Cintra (1972) faz referência é apresentado na obra de Machado (1967), tendo sido extraído da página 196 da obra de D. Francisco Manuel de Melo: “... nem me pisque os olhos, que vossê da história não sabe pisca”.

Se Cintra (1972) reproduz exatamente as informações contidas em Machado (1967), de onde viria a informação de que o primeiro registro de Você dataria de 1666? É

\footnotetext{
${ }^{1}$ Para padronizar o título do texto, utilizamos Feira dos Anexins. É possível, no entanto, que em algumas citações seja encontrada a forma alternativa Feira de Anexins, além de variações entre maiúsculas e minúsculas.
} 
bastante provável que essa informação tenha sido intensamente propagada na literatura a partir de outra obra fundamental. Trata-se do artigo intitulado $O$ tratamento você em português: uma abordagem histórica, do professor Carlos Alberto Faraco, publicado originalmente na revista Fragmenta, em $1996 .^{2}$ Vejamos o que nos diz Faraco:

Antes de encerrar essas observações históricas, devemos mencionar que cronologicamente o primeiro texto escrito a ter a forma você é Feira de anexins, escrito por Francisco Manuel de Melo e publicado em 1666 (cf. Machado, v. III, p. 2319) (FARACO, 1996, p. 63, grifo nosso).

Podemos observar que a fonte utilizada por Faraco (1996), assim como Cintra (1972), é o Dicionário Etimológico da Língua Portuguesa, de José Pedro Machado, que aponta para Feira dos Anexins como o primeiro texto escrito a ter registrada a forma Você. No entanto, diferentemente dos demais autores, Faraco (1996) afirma que o texto de D. Francisco Manuel de Melo teria sido publicado em 1666.

Sintetizamos essa transmissão das informações sobre a primeira abonação da forma de tratamento Você na figura abaixo:

Figura 1. Sobre a primeira abonação de Você a partir da literatura tradicional sobre o tema

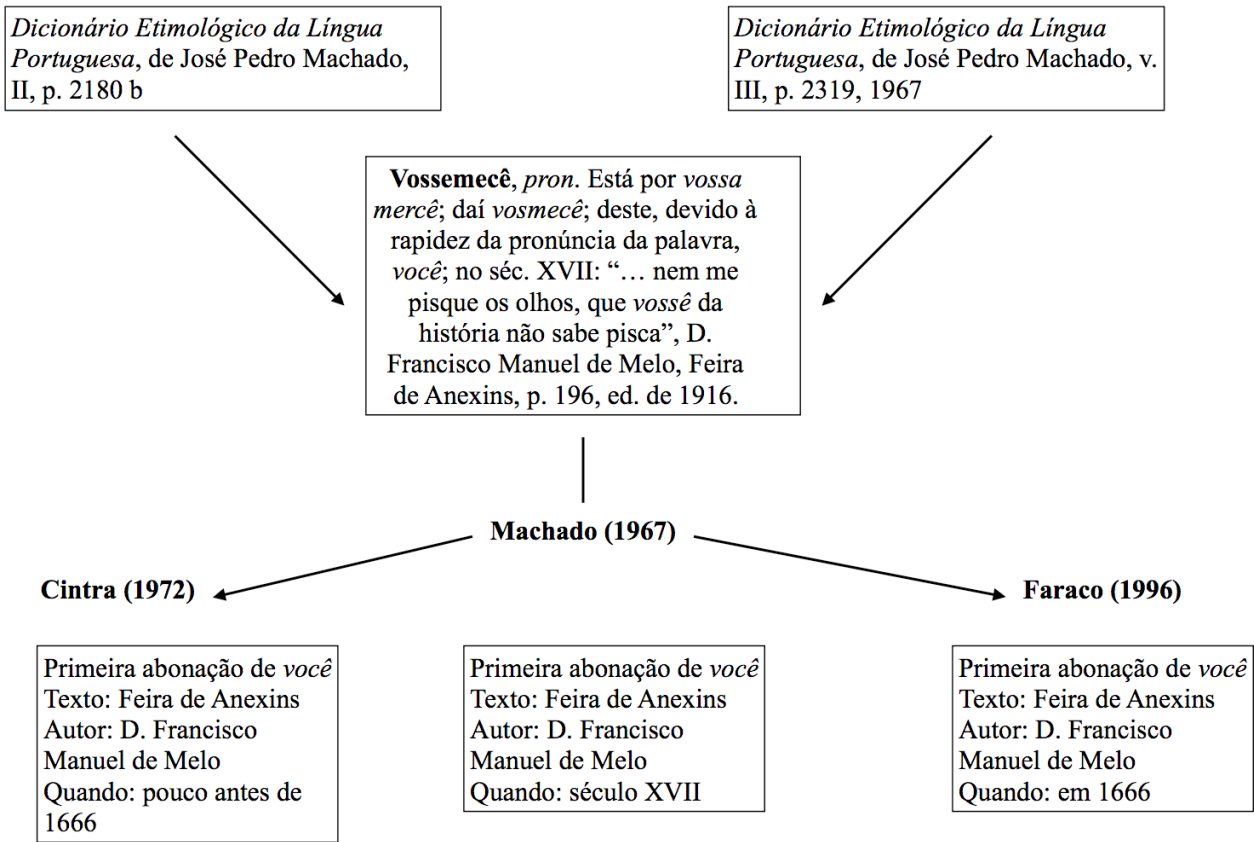

Fonte: Elaboração dos autores, 2019.

\footnotetext{
${ }^{2} \mathrm{O}$ texto do prof. Carlos Alberto Faraco, por sua elevada importância, foi reeditado recentemente e publicado na revista LaborHistórico (FARACO, 2017). No mesmo número em que foi publicado (volume 3, número 2, 2017), está disponível também o texto de Christiane Maria Nunes de Souza, intitulado Por que reeditar (e reler) "O tratamento você em português: uma abordagem histórica", no qual a autora discute a importância e a vitalidade do texto clássico de Carlos Alberto Faraco, assim como justifica a necessidade de sua republicação.
} 
Como se pode ver, Cintra (1972) e Faraco (1996) utilizam como fonte edições distintas do Dicionário Etimológico da Língua Portuguesa, de José Pedro Machado. A partir, no entanto, do mesmo conteúdo disponível no verbete Vossemecê, constroem, de forma distinta, a informação cronológica sobre o primeiro registro de Você. O texto original de Machado menciona o século XVII, século em que o autor de Feira dos Anexins, D. Francisco Manuel de Melo, teria vivido (1608-1666). Cintra (1972) aproveita a data de morte do autor como baliza limite para a elaboração do texto. Já Faraco (1996), ainda que, como os demais autores, tenha partido da edição de 1916 de Feira dos Anexins, oferece a data de 1666 para a publicação da obra.

São as informações propagadas por Faraco que parecem ter repercutido com mais intensidade na literatura sobre o tema e adquirem um valor simbólico de primeiro registro da forma de tratamento. Vejamos alguns exemplos:

O primeiro registro escrito de você data de 1666, em Feira dos anexins, de Francisco Manuel de Melo, o que nos faz concluir que sua circulação oral seja anterior a essa data, em Portugal (FERNANDES, 2009, p. 27, grifo nosso).

De acordo com Faraco (1996), o primeiro texto a mostrar a forma você data de 1666 (MARCOTULIO, 2008, p. 34, grifo nosso).

É interessante referir que o vocêé oriundo de uma forma honorífica, seguiu uma trajetória de modificação de valor ao lado da modificação fonética e esta teve seu primeiro registro no texto "Feira de anexins", escrito por Francisco Manuel de Melo, publicado em 1666 (cf. NASCENTES 1956 apud FARACO 1996, p. 63) (MOURA, 2013, p. 34, grifo nosso).

This form was documented for the first time in 1666 in the Feira de Anexins by Francisco Manuel Melo (cf. Soto, 1997). This is a familiar and common form of address used largely in Brazil. Its use in Portugal is minor (WILLIAMS, 2004, p. 4, grifo nosso).

Tratemos, agora, na próxima seção, do autor e de sua obra.

\section{Obra e autor: Feira dos Anexins, de D. Francisco Manuel de Melo}

D. Francisco Manuel de Melo nasceu em 23 de novembro de 1608 e faleceu em 24 de agosto de 1666. Era de uma ascendência nobre e sua formação durou cerca de dez anos na corte, em que solidificou a sua elevada posição social. Era escritor, político, moralista, historiador, epistolar, além de se voltar também para a vida espiritual (CHACOTO, 2008).

Silva (1875), no prefácio de Feira dos Anexins, considera que D. Francisco Manuel de Melo é um epíteto imortal e que suas obras são preciosidades:

É auctor pelo qual se deve estudar, porque é um d’aquelles em que se acham vocábulos exquisitos próprios da língua; e n'este ponto como os 
outros clássicos raras vezes usam (ou talvez nunca) de similhantes vozes, faz este escritor a mesma autoridade que fariam os primeiros mestres. Os seus diálogos, os seus versos e cartas servirão muito n'esta materia ao leitor pouco instruido (SILVA, 1875, p. 20-21).

De acordo com Menon (2006), suas principais obras, juntamente com a data de publicação, foram: Auto do Fidalgo Aprendiz (1646); Carta de Guia de Casados (1651); Apólogos Dialogais (1655); Epanáforas de Vária História Portuguesa (1660); Obras Morales (1664); Obras Métricas (1665); e, por fim, Feira dos Anexins (1666).

Feira dos Anexins (1666) ou Metáforas, como é conhecida, é uma das obras de D. Francisco Manuel de Melo, tendo sido publicada após a sua morte. Foi considerada como "talvez o mais eloquente arrazoado escripto na língua portugueza, modelo de vehemencia, sentimento e estylo" (SILVA, 1875, p. 10). Essa obra foi publicada pela primeira vez, em $1875^{3}$, por Inocêncio Francisco da Silva, e sua segunda edição, em $1916{ }^{4}$

Figura 2. Capas das edições de 1875 e 1916 de Feira dos Anexins, de D. Francisco Manuel de Melo
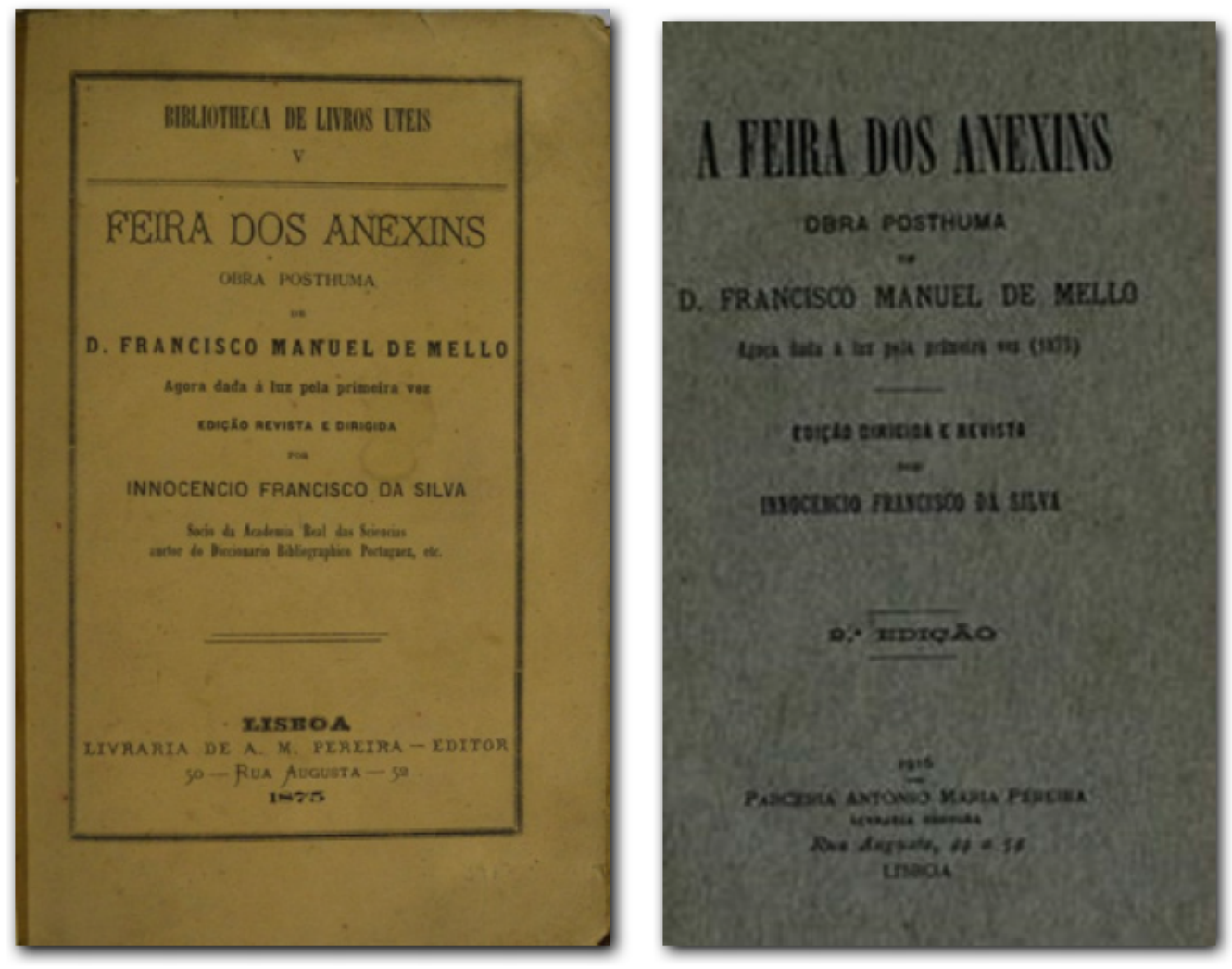

Fonte: Elaboração dos autores, 2019.

\footnotetext{
${ }^{3}$ Feira dos Anexins. 1875. [Obra posthuma de D. Francisco Manuel de Mello. Agora dada á luz pela primeira vez. Edição revista e dirigida por Innocencio Francisco da Silva.] Lisboa: Livraria de A. M. Pereira Editor.

${ }^{4}$ A Feira dos Anexins. 1916. [Obra posthuma de D. Francisco Manuel de Mello. Agora dada à luz pela primeira vez (1875). Edição dirigida e revista por Innocencio Francisco da Silva.] 2a edição. Lisboa: Parceria Antonio Maria Pereira - Livraria Editora.
} 
Segundo Chacoto (2008), a princípio seria a continuação de Apólogos Dialogais (1655), obra que, assim como Feira dos Anexins, também foi publicada postumamente. Para a autora, Feira dos Anexins pode designar um mercado, onde se vendem produtos, mas pode também significar confusão, desordem ou desafio. Anexins, por sua vez, são adágios, isto é, provérbios:

A obra Feira dos Anexins, publicada postumamente em 1875, se desenvolve por meio de um diálogo constante entre os personagens, que se propõem um desafio de anexins - provérbios, ditos populares (FERNANDES, 2009, p. 42).

A obra está dividida em três partes nas quais os personagens debatem o valor e a relevância dos anexins para o povo. $\mathrm{O}$ texto é construído a partir de diversos jogos de palavras, trocadilhos e metáforas. Na primeira delas, há seis diálogos; na segunda, há três diálogos; já a terceira difere das demais, sendo um conjunto de sete fábulas e não de diálogos como as anteriores. Os diálogos são curtos e objetivos, contendo provérbios e questionamentos.

Na primeira parte, o primeiro diálogo contém metáforas de cabeça, testa, cara, rosto, faces, olhos, nariz, boca, dentes, beiços, língua, queixo, barba, orelhas; no segundo diálogo, há metáforas sobre o corpo, pescoço, ombros, braços, mãos, dedos, unhas, peito, mama, barriga, estômago, pernas, pés; no terceiro diálogo, encontram-se metáforas de coração, sangue, tripas, bucho, fígado, pele, carne, humores; no quarto diálogo, estão metáforas de alma, potências, sentidos, dever, ouvir, cheirar, gostar, palpar; no quinto diálogo, as metáforas são de ações como chorar, rir, comer, beber, cuspir, cocar, andar, falar, dormir; e, por fim, no sexto diálogo, têm-se metáforas de cama, camisa, vestido, calça, espada, chapéu. Na segunda parte, o primeiro diálogo traz metáforas de Deus, céu, anjos, fogo, água, ar, terra; no segundo diálogo, as metáforas se referem a aves, animais, bichos, peixes, marisco; e, no terceiro diálogo, há metáforas sobre o ponto. Na terceira parte, como foi supracitado, há um conjunto de sete fábulas, referentes a flores, frutos, hortaliça, legumes, pão, carnes e pescados.

\section{De volta à datação de Você}

Se, por um lado, o primeiro registro de Você como pertencendo ao texto Feira dos Anexins, de D. Fransisco Manuel de Melo, escrito em 1666, é aceito e divulgado por muitos investigadores sobre o tema, como pudemos ver na primeira seção deste artigo, há, por outro, visões distintas acerca do assunto. Nesse sentido, trazemos, nesta seção, os trabalhos da professora Odete Menon. 
Em seus textos, Menon destaca o quão difícil é delimitar uma data para o primeiro registro de uma forma, já que qualquer data está sujeita a alteração e deve ser passível de contestação. Em seu texto de 2006, Menon acredita que a forma Você possa ter sido registrada primeiramente em Feira dos Anexins:

Até prova em contrário, é na obra de Francisco Manuel de Melo (16081666), Feira de Anexins, que aparece pela primeira vez o novo pronome, grafado vossê(s) (MENON, 2006, p. 129).

O texto de Feira dos Anexins, no entanto, levanta algumas questões interessantes relacionadas à sua datação. Em primeiro lugar, como mencionado anteriormente, não se sabe exatamente o ano de sua elaboração. A obra permanece manuscrita até 1875 , quando é primeiramente publicada, tendo sido republicada em 1916. Nesse sentido, a data de 1666 é atribuída à obra por ser a data de morte do autor.

Além disso, de acordo com informações levantadas por Menon (2009) a partir da obra de Serra (1998), o que condiz com a visão de Chacoto (2008), o texto de Feira dos Anexins poderia ser considerado como o esboço do quinto apólogo da obra Apólogos Dialogais. Assumir esse ponto de vista, no entanto, nos obriga a enfrentar uma questão importante se levarmos em consideração o repertório de formas de tratamento encontrado em cada obra:

Como o você não aparece nos quatro apólogos (somente a forma vossa mercê), seria de se perguntar se, no caso de o texto da Feira ser "passado a limpo" para publicação, a forma teria sido alterada pelo próprio autor ou se ela se manteria. $\mathrm{O}$ interessante a notar, também, é que na edição das Cartas Familiares, feita pelo próprio autor, não aparece nenhuma ocorrência de você: somente vossa mercê (abreviado, no mais das vezes, em V.M., na edição de Sarmento, 1981); o tratamento íntimo tu não aparece, nem nas missivas a amigos, nem aos parentes - a esses trata em geral por vós, V.M. ou V. S., conforme o caso. (MENON, 2009, p. 49).

A obra Feira dos Anexins, sendo ou não parte de Apólogos Dialogais, apresenta um comportamento diferenciado, não só em termos qualitativos, por apresentar registros de Você, como quantitativo, pelo elevado número de ocorrências se comparado às demais formas de tratamento empregadas.

A hipótese levantada por Menon (2009) referente à introdução de modificações no texto, elaborado no século XVII e publicado mais de dois séculos depois, pode ser 
interessante e mereceria investigação mais aprofundada. Sobre essa questão, cabe-nos registrar aqui o que é oferecido na Introdução da edição de 1875 - que também aparece na de 1916 - pelo editor da obra.

A partir da publicação de 1875, é possível ler, nos Preliminares, as seguintes palavras do editor Innocencio Francisco da Silva:

Fôra desejo do editor e nosso, que a presente edição viesse a lume elaborada sobre o texto ou original primitivo; porém quanto a este ponto sairam baldadas todas as pesquizas e diligencias, que um e outro empregámos. Destruido provavelmente pelas vicissitudes dos annos, $\underline{\text { não }}$ podemos d'esse original achar memoria ou vestigio em parte alguma.

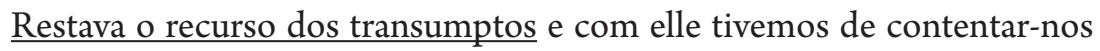
(SILVA, 1875, p. XII, grifo nosso).

Diante da ausência do texto original, a edição de 1875 tem como base transuntos, isto é, cópias. Dentre as cópias disponíveis, todas com letras do século XVIII, tem-se notícia de, ao menos, seis cópias, tendo sido possível consultar cinco delas ${ }^{5}$ :

Recorreu-se em primeiro logar ao sr. A. Herculano, que para logo annuiu do melhor grado á sollicitação, facultando benevola e liberalmente a copia que possuia, pelo que devemos consignar-lhe aqui um voto de agradecimento. Essa copia comtudo comprehendia apenas a primeira parte da Feira, faltando-lhe por conseguinte a segunda e terceira. Quanto a esta ultima, poderia de algum modo supprir-se com os excerptos que d'ella publicou o padre João Baptista de Castro na sua Hora do recreio.

No entretanto quiz a sorte d'esta vez favorecer-nos, deparando-nos a acquisição de outra copia (esta completa com as tres partes) que anteriormente pertencera ao finado conselheiro d'estado Fernando Luis Pereira de Sousa Barradas. E ultimamente fomos encontrar na Bibliotheca Nacional mais duas copias, uma tambem completa pertencente á livraria do celebre bibliophilo D. Francisco de Mello Manuel da Camara (vulgo o Cabrinha); outra só da primeira parte e assás incorrecta, que fôra comprada aos herdeiros de Manuel Thomas Pinheiro de Aragão. Todas (bem como a do sr. Herculano) são de lettra do seculo XVIII, e parecenos ser a nossa mais antiga entre todas. Diz-se ainda haver uma copia na Bibliotheca Eborense; porém quanto a esta faltou o meio de examinal-a. (SILVA, 1875, p. XII-XIV).

Sobre o texto fixado que é apresentado ao leitor, podemos ler como foi constituído a partir das cópias disponíveis:

\footnotetext{
${ }^{5}$ Para entender o processo de tradição e edição das cópias manuscritas, consultar Santos (1997).
} 
As [cópias] que estavam ao nosso alcance foram todas confrontadas, e conferidas tão minuciosamente quanto o permittiu o estado deteriorado da nossa vista, hoje pouco menos que extincta, aproveitando em cada uma as variantes, que mais genuinas nos pareceram. Cumpre ainda assim declarar que em alguns passos, apezar de conformes entre si, as julgamos todas viciadas: mas preferimos deixal-os taes quaes, a introduzir de lavra propria quaesquer emendas arbitrarias. Da mesma sorte não julgámos que nos fosse licito alterar ou modificar a lettra do texto, ainda n'aquelles logares em que o auctor, deixando correr a penna com maior liberdade da que talvez empregaria se destinasse elle proprio a obra para o prelo, usou de vocabulos ou phrases, hoje estranhaveis por ventura á delicadeza affectada dos ouvidos do nosso seculo. (SILVA, 1875, p. XIV-XV, grifo nosso)

Como se pode inferir a partir do excerto acima, é provável que nenhuma alteração tenha sido introduzida no tocante às formas de tratamento, já que houve a preocupação de manter as variantes mais genuínas do texto, por mais viciadas que pudessem parecer a um leitor do século XIX.

Devido ao problema da datação de Feira dos Anexins, Menon (2009) se utiliza de outra evidência, no conjunto total da obra de D. Francisco Manuel de Melo, e propõe que a primeira datação de Você seja recuada para o ano de 1665 - portanto um ano antes do ano de 1666, atribuído como ano de elaboração do texto. Em 1665 teriam sido publicadas, em vida do autor, as suas Obras Métricas, em três volumes:

Como as Obras foram publicadas em vida do autor, podemos afirmar, com alguma segurança, levando-se em consideração a sua data de nascimento (1608), que você(s) já seria moeda corrente em Portugal, pelo menos em Lisboa, desde o início do século XVII. (MENON, 2009, p. 50-51)

Nessas obras, além de formas como Vossa Mercê e Vossa Senhoria, Menon (2009) levanta algumas ocorrências de Você, tanto no singular, como no plural:

Ora tende, tende mão/ que vay o pano, e o Cabâs/ e fem razão fe lhes faz/ não dando delles razão,/ faço comemoração/ das ditas duas vazilhas,/ que fão tão honradas filhas/ que em vocé la as enchendo;/ tornarão logo, correndo/ a verme às mil maravilhas. (Obras, p. 211: Décimas XXVI, Da Ociozidade mandando hum queijo a hũa Dona.) (MENON, 2009, p. 50)

Bem está vocés agora, / eftarão muito contentes, / cuidando que fe acabou; / efta leitura perene./ Iaz aqui nefta algibeira:/ lindo como um ramalhete,/ cuberto de hũa celada,/ de rofas, e bem me queres,/ Armados de ponto embranco,/ para que todas as vezes; / que vocés differem:/ 
fayão, efta Academia atropellam./ Muficos meus amados ... (Obras, p. 213-214: Romance XXVII) (MENON, 2009, p. 50)

É bastante clara a importância do trabalho de Menon, no sentido de problematizar uma questão que é comumente aceita e sedimentada na literatura linguística. O mérito de Menon (2009), dentre tantos outros achados presentes no texto, é encontrar uma evidência datada no tempo que seja mais confiável do que as evidências disponibilizadas no texto da Feira. Uma investigação de natureza mais filológica poderia, por exemplo, recuar a própria datação da Feira, e, como consequência, esse texto continuar sendo, em princípio, o portador do primeiro registro de Você. Além disso, seria interessante ver a produtividade de Você no texto de 1665, bem como recuperar mais contexto para entender os dados oferecidos pela autora.

\section{Enfim, o texto e os dados}

Embora haja discussões acerca da validade de Feira dos Anexins como candidato ao texto que registra pela primeira vez a forma de tratamento Você, é notório, como tentamos mostrar, que é a partir dele, sobretudo com base em Faraco (1996), que a informação sobre a datação de Você é difundida, adquirindo um valor simbólico na literatura sobre o tema.

Esse texto, no entanto, permanece desconhecido por parte de muitos especialistas. De acordo com Menon (2009), Feira dos Anexins pode não ser uma obra tão difundida devido à sua natureza de obra rara:

[...] você vai aparecer consistentemente na Feira de Anexins (ver MENON, 2006) que, por infelicidade, permaneceu manuscrita até 1875 , quando foi publicada em edição organizada por Innocêncio Francisco da Silva (nela, o pronome aparece grafado Vossé). $\underline{\text { Como se trata de uma obra rara, parece }}$ $\underline{\text { se justificar sua não-menção por alguns autores que já se dedicaram ao }}$ estudo da trajetória do pronome você no português (MENON, 2009, p. 48-49, grifo nosso).

Feira dos Anexins é considerada uma obra teatral cômica, cujo texto está estruturado em diálogos, contando com a presença de distintos personagens. Sobre a natureza do 
texto e os recursos de linguagem empregados, observamos que:

Os turnos [de fala] baseiam-se no uso intenso de parônimos, homônimos, e homófonos, aproveitando-se do efeito cômico que o emprego desses termos provoca. Cada interlocutor se aproveita de uma deixa de outro participante do diálogo, para inserir sua exposição, sua crítica ou seu comentário. A estrutura do texto o aproxima, modernamente, de um desafio de repentistas, inclusive por seu caráter popular (FERNANDES, 2009, p. 42).

Uma especificidade está exatamente na identificação de personagens e cenário, que não estão descritos. A ausência dessa identificação, no entanto, pode dificultar a leitura do texto em muitos casos. Tomemos, por exemplo, a metáfora sobre o queixo:

\section{Parte I, 12. Em metaphora de queixo ${ }^{6}$}

- D’isso é que eu me queixo.

- A esse equivoco, fiquei eu de queixo caido.

- Agora estava eu, para lhe dizer que? Xó, bom pinote!

- Já de rir me doem os queixos, porque equivocos tão mal mastigados, fazem-me remoer de raiva e moer a paciência.

- Vamos marchando a outra metaphora; que falta para o primeiro dialogo, a barba.

A metáfora está composta por cinco intervenções em torno ao queixo. Vê-se, no texto, a presença de jogos de palavras e expressões cristalizadas como me queixo, de queixo caído e me doem os queixos. No entanto, não podemos identificar quantos personagens fazem parte desta cena e que falas podem ser atribuídas a cada um deles. Essa mesma metáfora poderia contar com a presença de dois personagens - A e B - que se alternam no diálogo:

\section{Parte I, 12. Em metaphora de queixo}

A: - D'isso é que eu me queixo.

B: - A esse equivoco, fiquei eu de queixo caido.

A: - Agora estava eu, para lhe dizer que? Xó, bom pinote!

B: - Já de rir me doem os queixos, porque equivocos tão mal mastigados, fazem-me remoer de raiva e moer a paciência.

A: - Vamos marchando a outra metaphora; que falta para o primeiro dialogo, a barba.

\footnotetext{
${ }^{6}$ Os fragmentos ilustrativos constam, em igual teor, das duas edições da obra (1875 e 1916).
} 
Ou até mesmo de cinco personagens distintos - A, B, C, D e E -, cada um com uma fala na cena:
Parte I, 12. Em metaphora de queixo
$\mathrm{A}:-\mathrm{D}$ 'isso é que eu me queixo.
B: - A esse equivoco, fiquei eu de queixo caido.
C: - Agora estava eu, para lhe dizer que? Xó, bom pinote!
D: - Já de rir me doem os queixos, porque equivocos tão mal mastigados, fazem-me remoer de raiva e moer a paciência.
E: - Vamos marchando a outra metaphora; que falta para o primeiro dialogo, a barba.

Se, por um lado, o texto teatral, por sua estrutura dialógica, se apresenta como uma excelente fonte para a seleção de formas de tratamento de segunda pessoa, a ausência de identificação e descrição dos personagens nos leva a repensar, em termos metodológicos, como depreender o valor do uso das formas nas diferentes relações sociais estabelecidas entre os personagens, isto é, seu valor pragmático.

Vejamos mais alguns exemplos de metáforas relacionadas a partes do corpo, com algumas formas de tratamento destacadas: ${ }^{7}$

\section{Parte I, 3. Em metaphora de cara}

- O senhor ainda não viu a cara ás metaphoras: assente em uma cousa, que se quizer metter-se a equivoquista, ha de ser descarado.

— Isso é velho.

- Vão brincar com a maçã do escaravelho: antes descarado, que ter duas caras.

- Sim, mas sempre cara de galhofa, ás vezes custa caro; e cara de aço nunca é boa.

- Não o nego, que para careta só cara de frade, e frade carola.

- Pois a minha cara defende a minha pousada: cara deslavada nunca a tive: equivocos, eu! qual carapuça!

— Vossêe, para defender a sua cára, fez do pousadeiro máscara.

\footnotetext{
${ }^{7}$ Embora também sejam registradas ocorrências da forma nominal de tratamento $o$ senhor, neste trabalho, nos limitaremos a considerar somente as formas pronominais Você, Vossa Mercê, Vós e Tu.
} 


\section{Parte I, 12. Em metaphora de barba}

- Para essa metaphora venho eu de barba feita.

- Bom anexim para um homem com barbas no rosto!

- Antes aquele foi de bigode.

- Por estas, que Barbosa não diria outro tanto.

- N'esses ditos é vossa mercê barbato.

- Nem me vi ainda tão abarbado como vossa mercê.

- Sim, tem lido Barbuda.

- Não; os seus equivocos são de Cancer.

- Podiam ser de Calderon nos papeis de barbas, se as deitar de remolho.

- Ao menos tiro-as melhor de vergonha.

- Barbas tem vossê para isso! O outro, que escapou por innocente a Herodes.

$[\ldots]$

De uma forma geral, já nos conta Menon (2006) sobre as formas encontradas no texto na posição de sujeito:

[...] em Melo o uso de vossê(s), já completamente pronominalizado, é muito freqüente, apesar de aparecerem todas as maneiras de se dirigir ao interlocutor: tu, vós, o senhor, Vossa Mercê. (MENON, 2006, p. 135)

Em Feira dos Anexins são inúmeros os exemplos de Você:

(1) Diga vossê alguma cousa.

(2) Vossê entesta comigo?

(3) Sim; e não nos franza a testa; porque vossê é o papa equívocos.

(4) A vossê ninguém lhe punha o punhal aos peitos para que falasse sério: vossê se offereceu sem peito.

A forma de tratamento Você, atestada com muita frequência no texto, coexiste com outras formas de tratamento. Juntamente com ela aparece Vossa Mercê, como aponta o exemplo (5):

(5) Vossa mercê é o mais honrado calca rabo d'esta terra. E bem podiam os senhores ter-lhe outro respeito.

Além dessa forma de tratamento, uma outra forma presente é Vós, como vemos em $(6-7)$ : 
(6) Homem, a mim ainda me não vieram os do siso; mas vós, que penteais discrições d'ancião, tereis dentes de cavallo marinho.

(7) Oh homem! Vós com ellas Paris?

Podemos notar também em (8-9) a presença da forma Tu:

(8) Também tu parece, que queres que te dente?

(9) Tu és meu amigo, homem; basta que m'amas?

Em termos quantitativos, temos os seguintes resultados para a posição de sujeito:

Tabela 1. Resultados quantitativos gerais: posição de sujeito

\begin{tabular}{|c|c|}
\hline Você & $395 / 412-96 \%$ \\
\hline Vossa Mercê & $7 / 412-2 \%$ \\
\hline Vós & $5 / 412-1 \%$ \\
\hline $\mathrm{Tu}$ & $5 / 412-1 \%$ \\
\hline
\end{tabular}

Fonte: Elaboração dos autores, 2019.

Foi possível recolher um total de 412 dados na posição de sujeito. Desse total, a grande maioria, 395 dados, se refere à forma Você, o que equivale a 96\% das ocorrências. As demais formas de tratamento apresentam baixa produtividade no texto: $2 \%$ de Vossa Mercê ( 7 dados); 1\% de Vós (5 dados); e 1\% de Tu (5 dados).

Focalizemos agora somente a forma Você. Além da posição de nominativo, isto é, sujeito (10), a forma Você também pode ser registrada nas demais posições sintáticas, como já apontava Menon (2006, p. 135): "Cabe ressaltar que vossê(s) apareceu em todas as funções gramaticais", tais como acusativo ou objeto direto (11), dativo ou objeto indireto (12), oblíquo ou complemento de preposição (13) e genitivo ou possessivo (14):

(10) Vossê é o que até agora nos lograva.

(11) Vossê, o descanço o faz crear barriga.

(12) A vossề, n'essas cousas, não se lhe embaraça tanto a lingua.

(13) Pois eu, nú em pelle me quero com vossê.

(14) Vossê, para defender a sua cara, fez do pousadeiro mascara.

Quantitativamente, temos os seguintes resultados: 
Tabela 2. Distribuição de formas do paradigma de Você de acordo com a relação gramatical

\begin{tabular}{|c|c|}
\hline Nominativo & $395 / 459-86 \%$ \\
\hline Acusativo & $12 / 459-3 \%$ \\
\hline Dativo & $41 / 459-9 \%$ \\
\hline Oblíquo & $8 / 459-2 \%$ \\
\hline Genitivo & $3 / 459-1 \%$ \\
\hline
\end{tabular}

Fonte: Elaboração dos autores, 2019.

De um total de 459 formas relativas ao paradigma pronominal de Você, a posição de sujeito (nominativo) é a mais produtiva, com $86 \%$ do total de dados (395 ocorrências). A relação de objeto indireto (dativo) é a segunda mais frequente no texto, com um total de $9 \%$ dos casos (41 dados). A menor produtividade é reservada aos contextos de objeto direto (acusativo), complemento de preposição (oblíquo) e possessivo (genitivo), com $3 \%, 2 \%$ e $1 \%$ de frequência, respectivamente.

Uma vez entendido que, no plano morfossintático, a forma de tratamento Você é a mais produtiva em Feira dos Anexins e pode ser encontrada em todos os contextos sintáticos típicos de formas pronominais, façamos uma breve incursão pelo terreno da pragmática. Como mencionado anteriormente, a exploração do valor social no uso da forma não pode contar com informações essenciais sobre a relação social estabelecida entre os interlocutores envolvidos no uso e recepção da forma, uma vez que os personagens não são identificados e descritos. Nesse caso, poderemos inferir em que relação social a forma está sendo utilizada a partir de formas auxiliares presentes em cada fala, como vocativos, adjetivos etc.

A partir de uma análise qualitativa dos dados extraídos da obra, podemos perceber que a forma pronominal $\mathrm{Tu}$ aparece no texto como uma forma de intimidade entre os interlocutores. Vejamos alguns exemplos:

(15) Tu és meu amigo, homem; basta que m'amas?

(16) Não são estas (respondia o meu desejo) as penas, que se devem lançar ao ar: se tu, amor, me prestares as azas, mas que me ameace o castigo d'Icaro, de boa vontade voara o meu desejo a ser Dedalo.

Por meio dos exemplos supracitados, pode-se depreender que o pronome Tu seja 
utilizado em relações simétricas, mais solidárias, leitura sugerida por formas que estão em destaque como "amigo" e "amor". No primeiro caso, em (15), a forma Tu poderia ser utilizada numa relação de amizade; já em (16), numa relação amorosa. Seja como for, não parece haver relações de poder ou hierarquia social entre os personagens envolvidos na cena.

Já a forma Vós parece ter um comportamento híbrido, transitando entre valores típicos de relações simétricas e assimétricas:

(17) Não sabeis, namorado coração, amante desejo, que são marés, e que aqui vos não quer o mar?

Em (17) é possível cogitar a utilização da forma Vós em relações sociais isentas de hierarquia, tal como as relações simétricas. Nesse exemplo, Vós é encontrado em contexto similar ao $T u$, no que se refere ao discurso amoroso, o que fica mais claro com a utilização de marcas como "namorado coração" e "amante desejo".

Já em relações assimétricas ascendentes (de inferior para superior), como ocorre no discurso religioso em (18), também podem ser encontradas ocorrências de Vós:

(18) São Luiz, dae fala ao menino!

Uma outra forma de tratamento que coexiste com Você em Feira dos Anexins é Vossa Mercê. Vejamos:

(19) N’esses ditos é vossa mercê barbato.

Em (19), temos um dado de Vossa Mercê em um contexto em que não se verificam diferenças de níveis hierárquicos entre os interlocutores, o que sugere uma relação simétrica, ainda que não seja de muita proximidade. Por outro lado, exemplos como (20) e (21) apontariam para uma forma de mais cortesia:

(20) Sou seu captivo, meu senhor: vossemecê que é mamposteiro, ahi ás mãos lavadas dirá o que quizer, que tem privilegio. 
(21) Vamos a outro capitulo, senhor capitão. Guie vossa mercê a metaphora.

Nos exemplos (20-21), temos por hipótese que essas ocorrências podem estar localizadas em diálogos de personagens inseridos em relações assimétricas ascendentes, isto é, de inferior a superior, o que pode ser inferido por "meu senhor' e "senhor capitão", por exemplo.

E, por fim, vejamos a forma de tratamento mais produtiva em Feira dos Anexins: Você. Tal como ocorre com Vossa Mercê, e também com Vós, a forma Você pode ser encontrada em relações hierárquicas e de maior distanciamento e respeito. Essa leitura pode ser depreendida pela utilização do vocativo "senhor":

(22) Basta, senhor; vossê em campo esgrimindo com a espada, olhe não lhe quebre os espelhos!

(23) Ah senhor, esse equivoco espetou vossê com o bicheiro.

Além desse uso, também podemos encontrar Você com caráter mais neutro, sendo uma forma compartilhada por um determinado grupo social, mesmo que não haja aproximação entre os interlocutores:

(24) Vossê é barba leda; não hade fazer tal, ainda que fora ao Barbado de Leça.

Em síntese, podemos tecer os seguintes comentários:

Figura 3. Valores pragmáticos das formas de tratamento: sistematização dos resultados

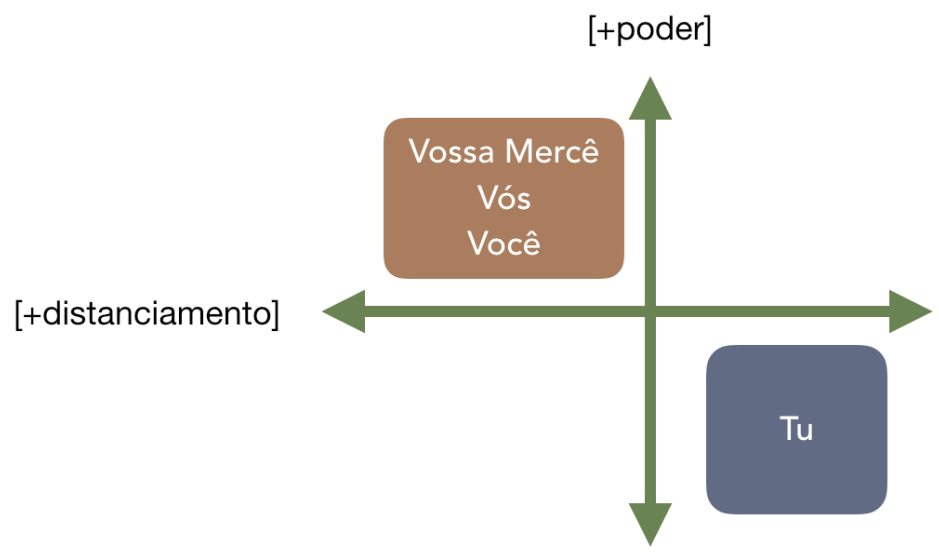

Fonte: Elaboração dos autores, 2019. 
O eixo vertical codifica informações sobre as relações que se dão em torno ao poder, ao passo que o eixo horizontal se refere às relações em torno à solidariedade. Neste último caso, embora não haja hierarquia entre os envolvidos na cena interativa, essas relações podem ser mais distantes ou mais íntimas.

Em Feira dos Anexins, a forma pronominal Tu parece ser utilizada em relações simétricas mais íntimas, de amor ou amizade. Vossa Mercê, Vós e Você, por outro lado, podem ser encontradas em relações simétricas, com mais ou menos distanciamento, além de relações assimétricas, sendo utilizadas de inferior para superior. Embora estejamos conscientes do limite de nossa análise, tendo em vista as dificuldades impostas pela natureza do texto, podemos entender, em sentido lato, que a forma de tratamento Você, ainda que se apresente sintaticamente ocupando, em maior ou menor medida, todos os contextos sintáticos específicos de uma forma pronominal, no plano pragmático parece não haver, ainda, uma diferenciação nítida entre a forma original Vossa Mercê e a nova forma em gramaticalização Você.

Pode-se, sim, depreender a partir dos dados o fato de Você parecer não ocupar os mesmos domínios de intimidade de $\mathrm{Tu}$, o que encontra eco na análise feita por Fernandes (2009):

\footnotetext{
Embora os personagens e o cenário não sejam descritos, imagina-se que o embate representa um desafio entre homens, em lugar público, sob assistência de outros, o que explica a preferência por você - mais respeitoso - a tu - extremamente íntimo e familiar -, durante todo o diálogo. Cabe lembrar que, mesmo hoje, em Portugal, o emprego de você mantém um distanciamento entre os interlocutores. Projetando-se para o passado, quando o pronome tinha maior proximidade cronológica com seu antecessor cerimonioso, Vossa Mercê, é de se esperar que o seu caráter distanciador fosse, no mínimo, igual ao atual (FERNANDES, 2009, p. 42, grifo nosso).
}

Como conclusão, é possível pensar em uma fotografia dinâmica, na qual Você coexiste com a forma original Vossa Mercê ainda nos terrenos da polidez, mas também apresenta usos diversos, típicos de processos de gramaticalização, como seu uso mais frequente em relações simétricas menos solidárias, sem, contudo, chegar a competir com $T u$ nos terrenos da intimidade.

\section{Duas datas, duas histórias}

Até aqui, demos a conhecer um pouco do texto Feira dos Anexins, de D. Francisco 
Manuel de Melo e exploramos as formas de tratamento encontradas, tanto em termos quantitativos, como qualitativos. Como tentamos deixar claro, ainda que haja propostas como a de Menon (2009) para que a data da primeira abonação de Você seja recuada de 1666 a 1665, não há, até onde sabemos, textos literários de momentos distintos à segunda metade do século XVII que possam ser possíveis candidatos a conterem o primeiro registro da nova forma de tratamento.

Se isso pode ser uma verdade momentânea para os textos literários, o mesmo não pode ser dito em relação a outras tipologias textuais. Uma busca em diversas plataformas de corpora do português nos mostra uma carta escrita em 1638 com o que pode ser, até agora, o primeiro registro de Você em textos não literários ${ }^{8}$.

Figura 4. Fac-símile de uma carta escrita em 1638 que contém a forma de tratamento Você

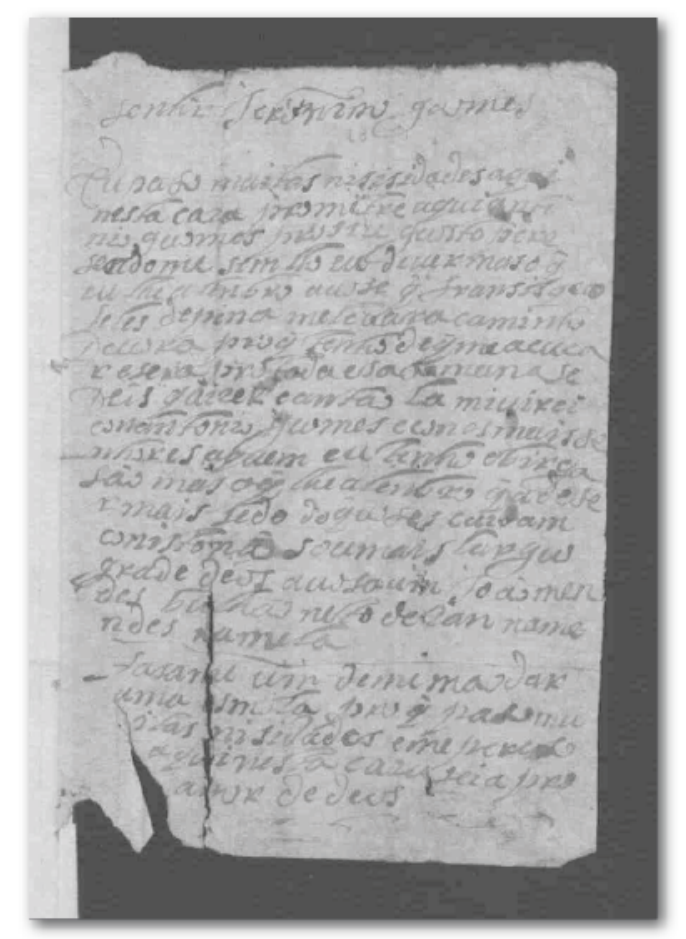

Fonte: Corpus P.S. - Post Scriptum, Arquivo Digital de Escrita Quotidiana em Portugal e Espanha na Época Moderna, CARDS4008.

Vejamos uma transcrição conservadora do texto: ${ }^{9}$

\footnotetext{
${ }^{8}$ A carta em questão pertence ao corpus P.S. - Post Scriptum, Arquivo Digital de Escrita Quotidiana em Portugal e Espanha na Época Moderna, organizado pela professora Rita Marquilhas da Universidade de Lisboa, disponível em <http://ps.clul.ul.pt $>$.

${ }^{9}$ Disponível em: http://ps.clul.ul.pt/index.php?action=file\&cid=Revistas/EdictorMerged/CARDS4008. xml\&jmp=w-35. Acesso em: 3 jan. 2019.
} 
senhor Jerónimo guomes

$\mathrm{Eu}$ paso muitas nisisidades aqui nesta caza pro me tre aqui antonio guomes pro seu guosto peresendome sem lho eu devermas o $q$ eu lhe alenbro a vose $q$ fransisquo teles de pina me levara caminho $\mathrm{D}$ evora proq tenho de $\mathrm{q}$ me acuzar e sera pro todaesa semana se

Deos quizer e antão la mi virei con antonio guomes e con os mais senhores a quem eu tenho obirgasão mas o qlhe alenbro $q$ a de ser mais sedo do q voses cuidam con isto não sou mais larguo grade deos a vosa vm

João mendes bulhão neto de janna mendes ramela

fasame vm de mi mãodar uma esmola proq paso muitas nisidades e me pereso aqui nesta caza seja pro amor de deos

Trata-se de uma carta não autógrafa escrita em 1638 por João Mendes Bulhão, cardador, preso em uma cadeia pública, para Jerónimo Gomes. No texto, o autor faz ameaças veladas ao destinatário e pede ajuda por estar passando necessidades na prisão.

A forma Você, grafada como vose, coexiste com a forma de tratamento original Vossa Mercê, na forma abreviada $v m$, sendo registrada uma única vez no singular, na posição de objetivo indireto (eu lhe alenbro a vose), e no plural, como sujeito (voses cuidam). Embora a coexistência entre a nova forma em gramaticalização e a forma original exista, tais formas não disputam as mesmas seções da carta: Você está presente no corpo da carta e Vossa Mercê em seções mais formulaicas como a despedida e o P. S.

No plano pragmático, no entanto, ambas as formas coexistem na codificação da mesma relação social. Ainda que haja atos ilocucionais diversos proferidos pelo remetente, ganham destaque a súplica e o pedido de ajuda, o que confere uma hierarquia à relação, podendo ser caracterizada como assimétrica ascendente, isto é, de inferior para superior. Nesse tipo de relação, observa-se o valor pragmático original de Vossa Mercê, de forma de respeito e distanciamento.

Parece, assim, que duas histórias diferentes precisam ser contadas: a história dos textos literários e a história dos textos não literários, caracterizados aqui pelos documentos epistolares. Essas histórias se justificam não somente pela datação (1665/1666, de um lado, e 1638, de outro), como também pelo valor pragmático sinalizado pelos textos.

Considerando exclusivamente textos literários, a literatura salienta um giro pragmático da forma Você, se comparada à forma original Vossa Mercê, e costuma descrevê-la como uma forma degradada e decadente, a partir dos séculos XVII/XVIII, sendo utili- 
zada em relações assimétricas descendentes, de superior para inferior, como mostram as palavras do filólogo Cintra e do dicionarista Bluteau:

Preocupação de muitos, antes de mais nada, em não serem tratados por Vossa Mercê e muito menos por uma das formas fonéticas decadentes vossancê ou você (esta última, salvo erro, atestada até agora pela primeira vez pouco antes de 1666), formas abreviadas intimamente associadas à degradação semântica da já antiga fórmula de cortesia (CINTRA, 1972, p. 27, grifo nosso).

Vossê. Trato usado com gente inferior, entre vòs, \& vossa mercè. (BLUTEAU, 1728, p. 580, grifo nosso).

Tudo leva a crer que o sabor depreendido de textos literários apontaria para uma forma de tratamento já em gramaticalização, distanciando-se da carga de polidez original que Vossa Mercê poderia comportar. Tem-se, assim, um descompasso entre a história contada pelos textos literários e a história contada pelos textos epistolares quanto ao valor pragmático do tratamento Você:

Imagem 3. Histórias da forma de tratamento Você em diferentes tipologias textuais: giros pragmáticos em relação à forma original Vossa Mercê

Textos não-literários: epistolares

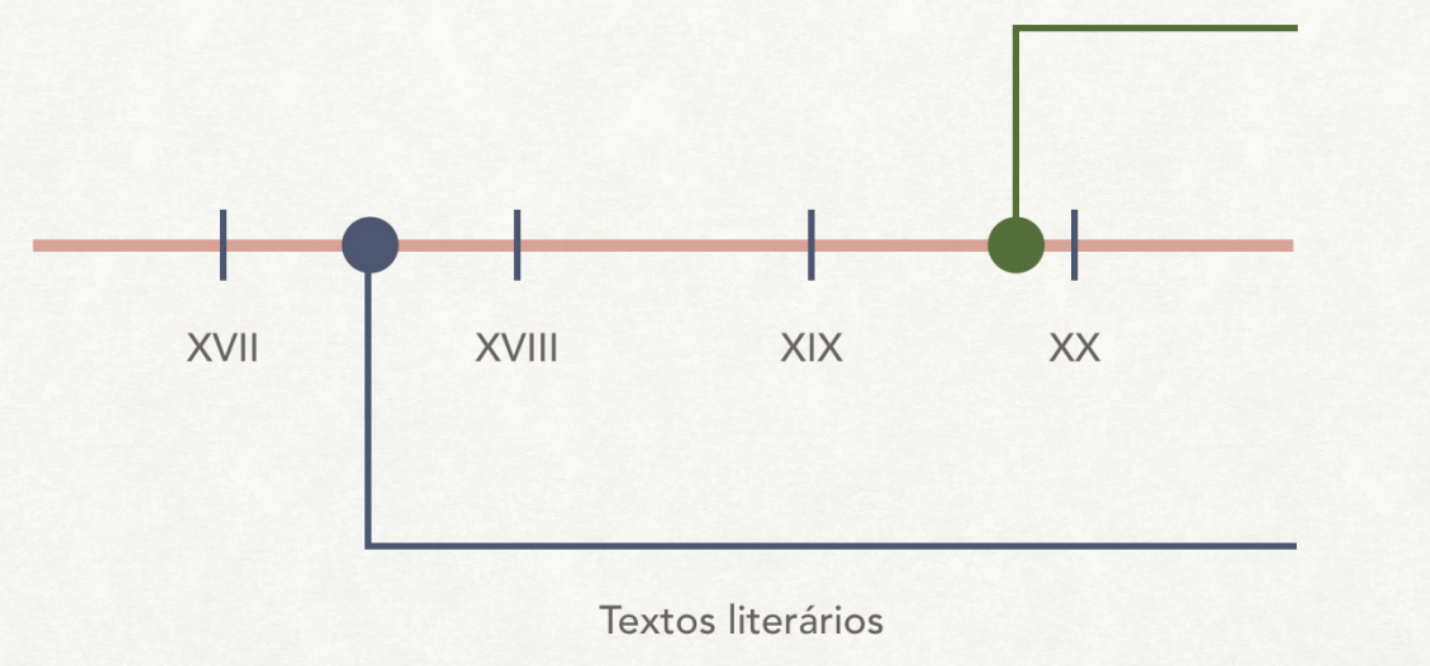

Fonte: Elaboração dos autores, 2019. 
Diferentemente do que ocorre com textos literários, em que se verifica um comportamento diferenciado entre Você e Vossa Mercê - mais acentuado nas palavras de filólogos e dicionaristas do que no texto que analisamos, Feira dos Anexins -, os documentos epistolares mostram que Você é capaz de manter seu caráter cerimonioso até fins do século XIX ou inícios do século XX, quando passa a disputar espaço com $T u$ nos terrenos da cortesia (RUMEU, 2013; LOPES et al., 2018; COSTA et al., 2018), ao menos no português brasileiro.

\section{Considerações finais}

Neste artigo, o nosso objetivo central foi dar a conhecer o texto intitulado Feira dos Anexins, de D. Francisco Manuel de Melo, assim como levantar elementos que permitissem a problematização da datação do primeiro registro da forma de tratamento Você. Sintetizemos, então, os pontos centrais.

Ainda que Feira dos Anexins tenha tido tanta difusão na literatura como candidato ao texto contendo o primeiro registro de Você, esse assunto, como tentamos mostrar, merece ser revisto. A datação de Você é questionada por Menon (2009), a partir dos seguintes argumentos: (i) a obra Feira dos Anexins é póstuma. A data de 1666 é atribuída em função do ano de morte do autor; (ii) tendo sido publicada somente em 1875, mais de dois séculos após a sua redação, a obra pode ter sido alvo de atualizações e intervenções por parte do editor; (iii) em termos mais linguísticos, Feira dos Anexins destoa das demais obras do mesmo autor e de outros textos coetâneos não somente pelo uso da forma Você em detrimento das demais formas de tratamento, como também pela sua elevada produtividade. As plataformas de corpora podem também auxiliar a discussão, disponibilizando uma carta de 1638 que contém um registro da nova forma de tratamento Você.

Ainda assim, devido ao "valor simbólico" adquirido pela obra e pela datação oferecida, foi de nosso interesse realizar uma investigação mais detalhada do texto. Em Feira dos Anexins, Você coexiste com outras formas de tratamento como Tu, Vós, Vossa Mercê e O Senhor. Em termos quantitativos, as taxas de uso de Você superam, em larga escala, as demais formas de tratamento. No plano sintático, Você ocorre na posição de sujeito (nominativo) e nas demais posições típicas dos pronomes, como objeto direto (acusativo), objeto indireto (dativo), complemento de preposição (oblíquo) e possessivo (genitivo). No que se refere à sua carga pragmática, diferentemente da forma $T u$, que só é registrada em relações simétricas de amor e amizade, a forma Você parece ser encontrada nos mesmos contextos de Vós e Vossa Mercê: relações simétricas menos solidárias e relações 
assimétricas ascendentes (de superior a inferior), marcando respeito e distanciamento. Esses resultados gerais sugerem um comportamento mais semelhante entre Você e a forma original que lhe deu origem Vossa Mercê.

Se considerarmos que os estudos com base em textos epistolares (RUMEU, 2013; LOPES et al., 2018; COSTA et al., 2018) mostram que Você se mantém como forma cortês de tratamento até o final do século XIX, esses resultados gerais podem evidenciar comportamentos distintos em função da tipologia textual: textos literários sugerem que, desde os primeiros registros, tem-se uma forma não só desgastada foneticamente, mas também pragmaticamente; por outro lado, textos epistolares parecem mostrar que o desgaste fonético não foi acompanhado pela perda de informações pragmáticas, uma vez que, nesse tipo de textos, Você continua sendo uma forma de cortesia até o final do século XIX ou início do XX.

\section{Referências}

CHACOTO, Lucília. La Feria de Anexins de Don Francisco Manuel de Melo: estudio literario y paremiológico. Critica del testo, XI/1-2, 2008, p. 31-42.

CINTRA, Luís F. Lindley. Sobre formas de tratamento na língua portuguesa. Lisboa: Livros Horizonte, 1972.

COSTA, Elizabhett Christina Cavalcante da; GOMES, Valéria Severina; SILVA, Cláudia Roberta Tavares. Variação e Tradição: uma análise do Tu e Você na posição de sujeito em cartas de pernambucanos (1860-1989). LaborHistórico, 4 (1), 2018, p. 55-71. DOI: https://doi.org/10.24206/lh.v4i1.17490

FARACO, Carlos Alberto. O tratamento “você” em português: uma abordagem histórica. Fragmenta 13, Publicação do Curso de Pós-Graduação em Letras da UFPR. Curitiba, Editora da UFPR. 1996.

FARACO, Carlos Alberto. O tratamento "você" em português: uma abordagem histórica. LaborHistórico, 3 (2), 2017, p. 114-132. DOI: https://doi.org/10.24206/ lh.v3i2.17150

FERNANDES, Elaine Cássia Pereira. Você como pronome de segunda pessoa no Brasil: motivações e percursos histórico, literário e gramatical. Dissertação (Mestrado em Língua Portuguesa). São Paulo: Pontifícia Universidade Católica de São Paulo, 2009.

LOPES, Célia Regina dos Santos et al. A reorganização do sistema pronominal de 2a pessoa na história do português brasileiro: a posição de sujeito. In: LOPES, Célia Regina dos Santos; CASTILHO, Ataliba T. de. (Org.). História do português brasileiro: mudança sintática das classes de palavra: perspectiva funcionalista. São Paulo: Contexto, 2018, v. 4, p. 24-141.

MACHADO, J. P. Dicionário etimológico da língua portuguesa. 2. ed. Lisboa: Confluência, 1967. 
MARCOTULIO, Leonardo Lennertz. A preservação das faces e a construção da imagem no discurso político do marquês do Lavradio: as formas de tratamento como estratégias de atenuação da polidez lingüística. Mestrado (Letras Vernáculas - Língua Portuguesa). Rio de Janeiro: Universidade Federal do Rio de Janeiro, 2008.

MENON, Odete P. S. A história de você. In: GUEDES, Marymarcia; BERLINCK, Rosane A.; MURAKAWA, Clotilde A. A. (Orgs.). Teoria e análise lingüísticas: novas trilhas. Araraquara: LEFCL/ São Paulo: Cult. Acadêmica, 2006. p. 99-160.

MENON, Odete P. S. Sobre a datação de você, ocê e senhorita. Fórum Linguístico, v.6, n. 1, Linguístico, Florianópolis. 2009, p. 45-71.

MOURA, Kássia Kamilla de. A implementação de você em cartas pessoais norte-riograndenses do século XX. Dissertação (Mestrado em Estudos da Linguagem). Natal: Universidade Federal do Rio Grande do Norte, 2013.

RUMEU, Márcia Cristina de B. A Implementação do Você no Português Brasileiro Oitocentista e Novecentista: Um Estudo de Painel. Doutorado (Letras Vernáculas - Língua Portuguesa). Rio de Janeiro: Universidade Federal do Rio de Janeiro, 2013.

SANTOS, Maria Sofia D. F. Godinho Silva. Feira dos anexins de Dom Francisco Manuel de Melo: estudo da tradição e edição. Mestrado (Literatura e Cultura Portuguesas - Época Moderna). Lisboa: Universidade Nova de Lisboa, 1997.

SOUZA, Christiane Maria Nunes de. Por que reeditar (e reler) "O tratamento você em português: uma abordagem histórica”. LaborHistórico, 3 (2), 2018, p. 108-113. DOI: https:// doi.org/10.24206/lh.v3i2.17149

WILLIAMS, Thomé. Sociolinguistic Aspects of Forms of Address in Portugal and Brazil: TU or VOCÊ. Intercultural Communication Studies XIII: 3, 2004.

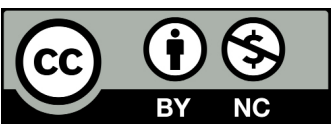

Data de submissão: 09/04/2019

Data de aceite: $27 / 10 / 2019$ 